\title{
EDITORIAL
}

\section{The politics, science and policy of reference points for resource management}

\begin{abstract}
... reference points should not be considered by themselves as targets of management. They may, homever, serve as signposts, and give some indication of phat consequences may lie in certain directions. . .
\end{abstract}

ICES Working Group, May 1983

Management of natural resources is notoriously complex. At its extremes, this complexity can be addressed through precise models of equilibrium dynamics or by coarse guidelines that seek to avoid unsustainable practices. Reference points have spanned this spectrum, beginning with ideas around optimum harvest (Ricker 1954) and trending towards avoiding collapse (Garcia 1994). After roughly 60 years of development, reference points have become an important component of sustainable practices and ecosystem based management of marine fisheries (Smith \& Sainte-Marie 2004). It has become apparent to many that the ideas inherent in reference points apply more widely than fisheries alone.

Adoption of reference points for fisheries policy began in the mid-1990s, when the UN Agreement on Straddling Fish Stocks and Highly Migratory Fish Stocks (Anon. 1995) and the USA's Magnuson-Stevens Fisheries Conservation and Management Act (Gabriel \& Mace 1999) identified reference points as a key approach to sustainable fisheries, recognizing that limit reference points, namely quantities defining a boundary between sustainability and degradation, can provide clear, precautionary guidance for fishers and managers as to when and how to alter spatial closures, temporal closures and fishing effort (Garcia 1994; Caddy \& Mahon 1995; Haigh \& Sinclair 1999). By constraining fisheries to operate within 'safe biological limits' (Anon. 1995), limit reference points allow fisheries managers to set traditional target reference points, such as maximum sustainable yield (MSY), that address short term economic goals while sustaining harvest over the long term (Caddy \& Mahon 1995).

The idea of using reference points for sustainable management was developed in the early 1980s by fisheries scientists with the International Council for the Exploration of the Sea (ICES) (Anon. 1984), who proposed that $\mathrm{F}_{0.1}$, the level of fishing at which an additional increase in effort leads to a $10 \%$ increase in yield (relative to the yield increase of fishing an unfished stock, $\mathrm{F}_{\max }$ ), provided a reasonable reference point for avoiding stock collapse. The choice of $10 \%$ was heuristic, based on advice from Gulland and Boerma (1973), to see how well it performed (for the foundation of reference points in fisheries management see Caddy \& Mahon 1995). Unfortunately, the $\mathrm{F}_{0.1}$ reference point went unimplemented due to political and economic fears that the fishing industry would suffer under potentially large yearto-year changes in quota (Rivard \& Maguire 1993; Walters \& Martell 2004; Cox et al. 2013). However the widespread collapse of industrialized fisheries has returned limit reference points to the forefront of fisheries science, increasingly as the basis of both harvest regulation (DFO [Department of Fisheries and Oceans Canada] 2004) and green certification schemes (Aschan et al. 2008).

Reference points have not been widely applied beyond fisheries but they have potential for managing any resource in need of regulation. Reference points are simply quantities related to the state of a resource at which management action is triggered or directed. Yet despite their conceptual simplicity, implementing reference points is a complex undertaking: where they are set and what action should be taken once they are surpassed presents a set of social and political issues that can exceed the technical difficulties inherent in their definition.

As a complex system managed under uncertainty, the social and ecological problems inherent in reference points have clear linkages to structured decision making (Holt \& Irvine 2013; Irwin \& Conroy 2013, this issue). Structured decision making is a framework for evaluating alternative management actions relative to their likelihood of meeting specified objectives (Irwin \& Conroy 2013), a process that includes identifying the management problem, defining stakeholder objectives, outlining management alternatives, estimating likelihoods or risks, and specifying the utility of potential outcomes (Conroy \& Peterson 2013; Holt \& Irvine 2013). Many elements of the structured decision process can include reference points as specific sub-components, each requiring substantial public, scientific and policy input to be implemented successfully.

Before a reference point can be implemented some level of understanding about the resource system is required. This knowledge can be approximate and coarse, as in a developing fishery where little is available beyond what is known about fisheries in general, or specific and detailed, as in a managed forest where every tree has been individually planted. In either case, the background knowledge of the system defines an environment that includes people engaged in resourcebased livelihoods, a management structure for regulation, and a finite resource. These elements frame the resource problem and unite stakeholders with an interest in its management.

The next step in defining reference points is for relevant stakeholders to articulate their views on current and ideal resource states, as well as to identify areas of potential concern. 
Reference points

Structured decisions

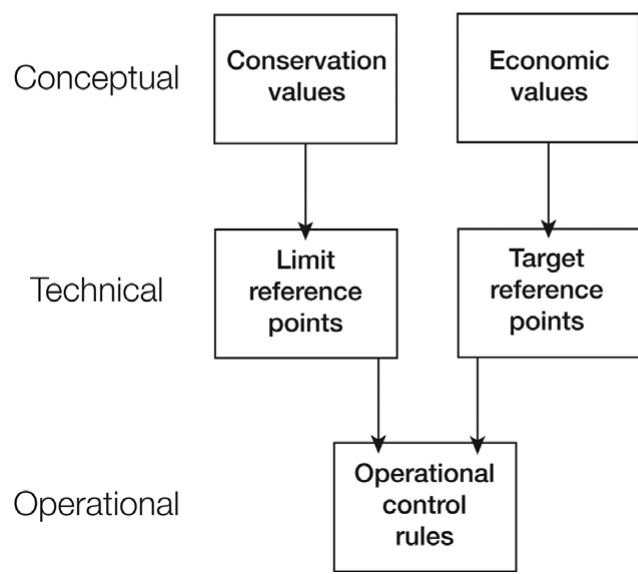

Objectives

Models

Actions

Figure 1 Schematic relationship between reference points and structured decisions in resource management.

These factors relate to beliefs, values and objectives that, often as not, vary widely among stakeholders and can generate tension about appropriate management. Structured decisions diminish these conflicts by specifying objectives at the outset, validating stakeholder positions and explicitly including their views in the management process. Here conceptual reference points can be established about resource objectives and concerns (Fig. 1). Conceptual reference points might include objectives such as 'maximize harvest over the long term', or concerns such as 'prevent negative population growth'. Conceptual reference points are important because they are statements through which values are often expressed, be they from harvesters, regulators, conservation groups or the public.

Conceptual reference points also provide the context for development of technical reference points, the hard numbers against which potential management action will be initiated. Fisheries scientists have spent a great deal of time defining technical reference points that require substantial quantitative and biological skill to estimate. MSY, $\mathrm{F}_{0.1}$, and $\mathrm{F}_{\max }$, for instance, are all affected by vagaries of catchability, effort and the spatial distribution of fish, each of which must be modelled statistically, estimated from data, or assumed unimportant. While technical reference points are often based on biological or ecological principles it is not necessarily so; parallels between biologically and socially-related values, states, and objectives suggest that social reference points can be developed in analogous ways for resources having a clear social dimension (Manning 2013, this issue).

In any context, definition of technical reference points should fundamentally be a process of accounting for uncertainty (Caddy \& McGarvey 1996; Prager et al. 2003), including both observational uncertainty, relating to the partially observed state of resource, and structural uncertainty, relating to the processes affecting the resource. Observational uncertainty can be addressed mechanically by collecting additional data, or statistically, by assuming a specific kind of error distribution for observations (Hilborn \& Mangel 1997; Irwin \& Conroy 2013). Structural uncertainty, however, is more subtle to detect and difficult to address. Researchers tend to deal with it by relying on familiar approaches and assuming they know the resource well enough to ignore it altogether (Burgman 2005). Often these approaches obscure large inconsistencies between models and reality.

Dealing with structural uncertainty has become a key area of research in setting reference points because it can markedly affect the definition of technical reference points that affect harvest levels (Cox et al. 2013). Structured decision theory addresses structural uncertainty by formally incorporating alternate hypotheses about how the resource system works and evaluating the likelihood of each model in light of available data, supporting some ideas and discounting others (Conroy \& Peterson 2013). When combined with periodic decision making and monitoring in an adaptive management framework, structural uncertainty is reduced further by learning about the resource system as it changes in response to management action (Irwin \& Conroy 2013).

Development of multiple models is not, however, the only approach for addressing structural uncertainty. Buffering capacity can be added to the system using operational control points (Fig. 1), quantities developed through consultation with stakeholders and managers that are set on the conservative side of technical reference points (Cox et al. 2013). Where exactly they are set is determined through experience, consultation, and simulation across potential models, leading to a defensible process for implementing reference points that both insures against structural uncertainty and provides agency for stakeholders in the regulatory process. When implemented in the sablefish Anoplopoma fimbria fishery in British Columbia, operational control points successfully reduced economic losses and ensured a negligible probability of breaching a key limit reference point (Cox et al. 2013, this issue). By helping to operationalize sustainability objectives for the fishery, operational control rules increased the effectiveness of biological reference points in the face of structural uncertainty.

While effective approaches for reducing structural uncertainty have been developed, they can also be informationhungry, demanding some level of understanding about the resource and somewhat reliable data. Where data are sparse, limit reference points can be conservatively invoked, using available information to establish acceptable impact or population boundaries for a specified level of risk. For instance, potential limit reference points for bycatch species in longline fisheries might include an impact limit on the rate of bycatch mortality, defined against a minimum set of vital rates for each species, to keep the number of bycatch deaths above replacement (Moore et al. 2013, this issue).

Where some sort of survey data are available, a more conventional population limit might be invoked based upon estimated population size, however these estimates are highly uncertain when data are limited (Moore et al. 2013). 
Population limits can be tested to some extent across a range of assumptions via simulation, where population viability is estimated across a range of values to identify thresholds where big state changes might occur, allowing the management system to avoid these areas.

Biologists tend naturally to favour the technical aspects of point estimation for biological reference points, however technical reference points can fail to meet stated objectives where managers fail to recognize the context, values and utilities (satisfaction with a given outcome) inherent in the decision making process (see for example Charles 1995). In Canada in the $1990 \mathrm{~s}$, a system of biological reference points was developed to manage Atlantic groundfish, with scientists consulted and technical reference points derived. Yet rather than adopting them directly, DFO managers devised a ' $50 \%$ rule' that split the difference between lower limit reference points and the previous year's quota according to a formula:

$$
F_{\text {next }}=F_{\text {current }}-\left(\frac{F_{\text {current }}-F_{0.1}}{2}\right)
$$

with the next year's catch allocation $\left(F_{\text {next }}\right)$ being halfway between last year's allocation $\left(\mathrm{F}_{\text {current }}\right)$ and what was recommended $\left(\mathrm{F}_{0.1}\right)$.

The $50 \%$ rule was intended to buffer sizeable cuts in quota due to large stochastic changes in population size (Rivard \& Maguire 1993), reflecting the mandate of many resource managers to simultaneously support industry and to protect stocks, with the often hidden assumption of equal utility for both outcomes. However equal weighting of economic and biological objectives is consistent only with target reference points; limit reference points are designed to constrain the management system and cannot, by definition, be breached once adopted. By repeatedly breaching $\mathrm{F}_{0.1}$ limits, DFO managers allowed continued overfishing of groundfish stocks, contributing to the loss of numerous fisheries (Charles 1995; Grafton et al. 2000).

The failed implementation of reference points in Canadian fisheries illustrates that, without meeting longterm conservation goals (namely, sustaining the resource), short-term economic considerations can quickly undermine a resource, generating both economic and biological failure. It also suggests that in some cases the quantities developed by biologists should be kept distinct from management reference points invoked by regulators to clarify the role of biological, social, and political information affecting regulation decisions (Holt \& Irvine 2013, this issue).

Clear distinctions between biologists and managers helped regulate Atlantic salmon Salmo salar fisheries in Norway, where populations had declined over many decades due to habitat degradation and overexploitation. To address these losses, the Norwegian government implemented a reference point based management strategy in 2008, with the primary goal of conserving salmon populations and a secondary goal of maximizing yield (Forseth et al. 2013, this issue). A national policy putting conservation first reflected Norwegian public attitudes, leading to a prioritized implementation of limit and target reference points that proved successful in meeting conservation objectives over the short term, with maximum fisheries yield seen as being achievable over the longer-term (Forseth et al. 2013). This shows that the effects of limit reference points, intended to ensure the long-term conservation of a resource, can occur rapidly after implementation, while target reference points, favouring short-term economic objectives, respond over longer time frames. It also suggests optimizing both objectives is ultimately a long-term proposition, requiring substantive regulatory control.

Despite the success of national reference points in Norwegian rivers, in many jurisdictions, federal fisheries policies have been ineffective due to factors such as poverty traps and lack of enforcement (Cinner 2011). This has led to a push for community-based governance and co-management that has proved successful for improving fisheries outcomes where, for example, people have a strong sense of agency over their resource (Cinner et al. 2012). This was the case in New Caledonia, where local bêche-de-mer fishers elected to close their fishery in 2007 in response to a decline in commercial sandfish Holothuria scabra landings, asking the provincial fisheries agency to assist in developing reference points for recovery (Léopold et al. 2013, this issue). Together, fishers and managers initiated an adaptive reference point system that set a cooperatively-defined reference biomass level of harvestable catch each year, using an operational control rule to set total allowable catch less than or equal to the lower $95 \%$ confidence interval of the target reference point. By adopting a target reference point with an operational control limit, benefits accrued rapidly in the fishery, within two sea cucumber generations.

The dominant narrative for open access resource use is that it leads to collapse, the 'tragedy of the commons' (Hardin 1968), while effective regulation meets the objectives of resource users and preserves the resource itself. A key failure of resource policy, in fisheries most famously, is the notion that economic and conservation objectives should be 'balanced', so that the economy gives up some profit to support conservation and conservation gives up some of the resource to support the economy. However assumed equality between conservation and economic interests undermines sustainability over the long term as the replacement capacity of the renewable resource is eroded by incremental overharvesting in response to economic pressure. Failure to prioritize conservation leads to the failure of both objectives more slowly than with the prioritization of economic interests alone.

Reference points can overcome the ratcheting effects of purportedly balanced harvest decisions by explicitly prioritizing conservation over harvest while allowing harvest to operate freely within specific constraints. This is how limit reference points should work, setting prerequisite conditions for economic objectives defined through target reference points. While limit reference points were explicitly developed to highlight areas where increased fishing would likely damage stocks irreparably (Caddy 2002), their importance 
as conservation constraints to economic targets is only just being recognized (for example Forseth et al. 2013). With a prenegotiated limit reference point from harvesters and regulators (Caddy 2002; Cox et al. 2013), the economic interests inherent in optimal yield are free to operate within a specified range.

Despite the power of reference points in managing a range of fisheries, restoration of overfished stocks has been inconsistent to date (Worm et al. 2009) as multispecies fisheries restoration has suffered from the inherent difficulties of managing different growth and mortality rates that simultaneously require different reference points (Caddy \& Agnew 2005). These multispecies issues are not insurmountable however, rather they require a more considered process than for managing a single stock or resource. For example, in fisheries a 'traffic light system' has been introduced that incorporates multiple indicators of ecosystem change, including both social and ecological factors (Caddy 2002).

Although developed within fisheries, the principles inherent in limit and target reference points should be applicable to any managed resource. There are social, technical and political obstacles to implementing reference points that are common among harvested systems; by addressing each of these explicitly as part of the regulatory process, implemented reference points have proved effective for managing and rebuilding reusable resources. Key principles include stakeholder engagement, clear targets and limits, and objective implementation. The specific details for each of these principles are context-specific, however they provide a framework upon which a resource system can develop effective longterm management that prioritizes conservation and values economic interests. It is hoped that the examples included in this special issue will contribute to the wider implementation of reference points across natural resource disciplines.

\section{ACKNOWLEDGEMENTS}

Thanks to S. Smith for engaging discussions on the development of reference points in Northwest Atlantic fisheries, and C. Hicks for comments on an early draft of this paper. This work is supported by the Australian Institute of Marine Science.

\section{References}

Anon. (1984) Reports of the working group on methods of fish stock assessments. Cooperative Research Report 129, International Council for the Exploration of the Sea, Copenhagen, Denmark.

Anon. (1995) Agreement for the implementation of the provisions of the United Nations convention on the law of the sea of 10 December 1982 relating to the conservation and management of straddling fish stocks and highly migratory fish stocks. In: United Nations Conference on Straddling Fish Stocks and Highly Migratory Fish Stocks. Volume Sixth Session, page A/CONF. 164/37, New York, 24 July-4 August 1995. United Nations, New York, NY, USA.

Aschan, M. Powels, H. Bannister, C. Hough, A. \& Knapman, P. (2008) Public certification report for Canadian northern prawn trawl fishery, shrimp fishing areas 13, 14, 15. Marine Stewardship Council Certification FN 82024, Moody Marine, Derby, UK.

Burgman, M. (2005) Risks and Decisions for Conservation and Environmental Management. Cambridge UK: Cambridge University Press.

Caddy, J. (2002) Limit reference points, traffic lights, and holistic approaches to fisheries management with minimal stock assessment input. Fisheries Research 56: 133-137.

Caddy, J. \& Agnew, D. (2005) An overview of global experience to date with recovery plans for depleted marine resources and suggested guidelines for recovery planning. Reviems in Fish Biology and Fisheries 14: 43-112.

Caddy, J. \& Mahon, R. (1995) Reference points for fisheries management. Fisheries Technical Paper 347, Food and Agriculture Organization of the United Nations, Rome, Italy.

Caddy, J. \& McGarvey, R. (1996) Targets or limits for the management of fisheries? North American fournal of Fisheries Management 16: 479-487.

Charles, A.T. (1995) The Atlantic Canadian groundfishery: roots of a collapse. Dalhousie Lam Fournal 18: 65-83.

Cinner, J. McClanahan, T. MacNeil, M. Graham, N. Daw, T. Mukminin, A. Feary, D. Rabearisoa, A. Wamukota, A. Jiddawi, N. Campbell, S. Baird, A. Januchowski-Hartley, F. Hamed, S. Lahari, R. Morove, T. \& Kuange, K. (2012) Co-management of coral reef social-ecological systems. Proceedings of the National Academy of Sciences USA 109: 5219-5222.

Cinner, J.E. (2011) Social-ecological traps in reef fisheries. Global Environmental Change 21: 835-839.

Conroy, M. \& Peterson, J. (2013) Decision Making in Natural Resource Management: A Structured, Adaptive Approach. Chichester, UK: Wiley-Blackwell.

Cox, S., Kronlund, A. \& Benson, A. (2013) The roles of biological reference points and operational control points in management procedures for the sablefish (Anonplopoma fimbria) fishery in British Columbia, Canada. Environmental Conservation (in press).

DFO (2004) A policy framework for the management of fisheries on Canada's Atlantic coast. Technical report, Department of Fisheries and Oceans Canada, Ottawa, Canada.

Forseth, T., Fiske, P., Barlaup, B. Gjøsaeter, H. Hindar, K. \& Diserud, O. (2013) Reference point based management of Norwegian Atlantic salmon populations. Environmental Conservation (in press).

Gabriel, W.L. \& Mace, P.M. (1999) A review of biological reference points in the context of the precautionary approach. In: Proceedings of the Fifth National NMFS Stock Assessment Workshop: Providing Scientific Advice to Implement the Precautionary Approach Under the Magnuson-Stevens Fishery Conservation and Management Act. NOAA Tech Memo NMFSF/SPO-40, pp. 34-45. NOAA, USA.

Garcia, S.M. (1994) The precautionary principle: its implications in capture fisheries management. Ocean and Coastal Management 22: 99-125.

Grafton, R.Q. Sandal, L.K. \& Steinshamn, S.I. (2000) How to improve the management of renewable resources: the case of Canada's northern cod fishery. American Fournal of Agricultural Economics 82: 570-580.

Gulland, J. \& Boerma, L. (1973) Scientific advice on catch levels. Fishery Bulletin 71: 325-335.

Haigh, R. \& Sinclair, C. (1999) Science strategic project on the precautionary approach in Canada. Proceedings of the Second Workshop. Volume 99, Nanaimo, Canada. Department 
of Fisheries and Oceans, Canadian Stock Assessment Proceedings Series.

Hardin, G. (1968) The tragedy of the commons. Science 162:12431248.

Hilborn, R. \& Mangel, M. (1997) The Ecological Detective. Number 28 in Monographs in Population Biology. Princeton, USA: Princeton University Press.

Holt, C. \& Irvine, J. (2013) Distinguishing benchmarks of biological status from management reference points: a case study on Pacific salmon in Canada. Environmental Conservation (in press).

Irwin, B. \& Conroy, M. (2013) Consideration of reference points for the management of renewable resources under an adaptive management paradigm. Environmental Conservation (in press).

Léopold, M. Cornuet, N. Andrèfoüet, S. Moenteapo, Z. Duvauchelle, C. Raubani, J. Ham, J. \& Dumas, P. (2013) Comanaging small-scale sea cucumber fisheries in New Caledonia and Vanuatu using stock biomass estimates to set spatial catch quotas. Environmental Conservation (in press).

Manning, R. (2013) Social norms and reference points: integrating sociology and ecology. Environmental Conservation (in press).

Moore, J., Curtis, K., Lewison, R., Dillingham, P., Cope, J., Fordham, S., Heppell, S., Pardo, S., Simpfendorfer, C., Tuck, G. \& Zhou, S. (2013) Evaluating sustainablity of fisheries bycatch mortality for marine megafauna: a review of conservation reference points for data-limited populations. Environmental Conservation (in press).
Prager, M., Porch, C., Shertzer, K. \& Caddy, J. (2003) Targets and limits for management of fisheries: a simple probability-based approach. North American Fournal of Fisheries Management 23: 349-361.

Ricker, W. (1954) Stock and recruitment. Fournal of the Fisheries Research Board of Canada 11: 559-623.

Rivard, D. \& Maguire, J.-J. (1993) Reference points for fisheries management: the Eastern Canadian experience. In: Risk Evaluation and Biological Reference Points for Fisheries Management, Volume 120, ed. S. Smith, J. Hunt \& D. Rivard. Canada: National Research Council of Canada.

Smith, S. \& Sainte-Marie, B. (2004) Biological reference points for invertebrate fisheries: introduction. Canadian Fournal of Fisheries and Aquatic Sciences 61: 1303-1306.

Walters, C. \& Martell, S. (2004) Fisheries Ecology and Management. Princeton, USA: Princeton University Press.

Worm, B., Hilborn, R., Baum, J., Branch, T., Collie, J., Costello, C., Fogarty, M., Fulton, E., Hutchings, J., Jennings, S. et al. (2009) Rebuilding global fisheries. Science 325: 578585 .

\section{AARON MACNEIL}

Australian Institute of Marine Science, $P M B 3$

Tomnsville MC 4810 QLD, Australia

e-mail:a.macneil@aims.gov.au 